\title{
A Probe into the Utilization of New Materials in Naxi Residential Door Trim of Lijiang Yunnan Province
}

\author{
Qiaoling Gui ${ }^{1, \text { a }}$, Xinyu Suo ${ }^{2, \mathrm{~b}}$, Feng Su ${ }^{1, \mathrm{c}}$, Ruibo $\mathrm{Hu}^{3, \mathrm{~d}}$, Yue $\mathrm{Yu}^{1, \mathrm{e}}$ \\ ${ }^{1}$ Kunming University of Science and Technology, Kunming, P.R.China \\ ${ }^{2}$ Yunnan University of Nationalities School of Vocational technical Educayion, Kunming, P.R.China \\ ${ }^{3}$ Guizhou Normal University ,Guiyang, P.R.China \\ amysjgzs@126.com, ${ }^{\mathrm{b}} 407904118 @ q q . c o m,{ }^{\mathrm{c}} 417640897 @ q q . c o m,{ }^{\mathrm{d}} 382035061 @ q q . C o m$
}

Keywords: wood, Naxi houses, door trim, new materials

\begin{abstract}
Based on the admiration towards the function, style and skills of Naxi residential door trim of Lijiang Yunnan Province, this paper investigates Naxi people's proper use of modern decorative art and new materials. The use of new materials not only makes up for the defect of traditional materials, but also widens decorative themes of the door trim, enriches decorative arts of the Naxi door trim and contributes to the development of the Naxi residential architecture. The article points out that the Naxi dwellings' traditional door decoration has its inadequacies in the aspect of decorative material and the Naxi dwellings' traditional door decoration represents Naxi people's open, inclusive and innovative characteristics.
\end{abstract}

\section{Introduction}

The main habitat of the Naxi people is in Lijiang, Yunnan Province, which is also the place originated Naxi culture. The Lijiang Naxi Autonomous Region is located in the northwest of Yunnan Hengduan Mountains where the geological structure is complex with climate variability, rich natural resources, long history and culture and many neighboring ethnic groups around. With fairly obvious geographical features, the place has blended the advanced culture of a large number of Han and other ethnic minorities in the process of its formation and development, which makes it a more mature ethnic minority area than other ethnic areas in Yunnan in its profound culture and long history. This reflects in the Naxi traditional dwellings more significantly. Door, as the entrance of the entire building, plays the role of defending and protecting, showing status, exorcising ghosts and absorbing luck. The Naxi door ornaments are full of cultural meaning and spirituality. Being attracted by the Naxi door trim culture, the author applied for a student extracurricular academic Innovation Fund of Kunming University of Science and Technology in 2012 and set up the project on "The Research of Naxi Residential Door Trim Decorative Art of Lijiang Yunnan ". In order to study the Naxi Door trim culture better, the author went to Dayan Town, Shuhe Ancient Town and Naxi inhabited villages in Lijiang in early 2012 to carry out field research. Lijiang Naxi residential door trim decoration has a strong ethnic regional feature with the essence of Naxi residential architecture and the fusion of geographical culture, customs and crafts after a thousand years of history and cultural accumulation. Naxi people in Yunnan multicultural pooled land has retained their own unique culture cultivation and aesthetic taste with the multi-ethnic and multi-form culture conflict, exchange and integration. They also established the open, inclusive, eclectic characteristics and the bold spirit of innovation. In recent years, with the influx of new material and modern decorative art, Naxi people has appropriately used a variety of new materials with the combination of the overall style of the residential environment, which not only makes up for the defect of traditional wooden materials but also revitalizes decorative arts of Naxi residential doors. It shows that Naxi people are prominent in widely absorbing other ethnic groups' strong points for the development of its own characteristics. Exposure to the Naxi courtyard, you can really feel the harmonious state of the ancient and the modern collision. 


\section{Characteristics of the traditional Naxi residential door decoration}

In the course of the development in nearly one hundred years, Naxi residential buildings combines the strengths of other regions and ethnic groups to its own national characteristics and has gradually formed its own characteristics in the decorative arts, the plane layout and structure. Most of Lijiang Naxi houses are the civil engineering structures with a large proportion of the wooden structure in the wall. The common forms of its construction are as following: Three lanes and one screen, four rooms with five yards, front yard and back yard, two-courtyards with one entrance and so on. The building pattern of "four rooms with five yards " is the legacy of the traditional Naxi culture. Four square lanes form the quadrangle courtyard. Four Square connecting parts become a small yard respectively. The large patio in the middle is the most public space and is the place to hold a variety of family activities. Four small yards assist living space and has the function of ventilation and day lighting [1]. In each entrance of the courtyard, the door plays an extremely important role which goes with the truth that "Home portal is crowned". The door trim which catches people's eyes and gives outstanding visual impression of art is an integral part of Naxi traditional dwellings. Naxi residential doors decorative art is closely linked with the ancient Naxi culture. It embodies the Naxi traditional humanistic ideas, reflects Naxi folk art heritage and witnesses substantial regional folk culture. The door decorative art modeling pattern, as the minority thinking vector art, conveys strong cultural connotations.

Features of Lijiang Naxi door trim decoration. Naxi houses door decoration materials are mainly made of wood. From the aspect of door's function, it can be divided into the outer door and the inner door, namely, the courtyard door and interior room doors. The outside door (the courtyard door) is usually the double-leaf door with its wooden components, such as the door, plaques, lintel, threshold, brackets, door auxiliary and iron door knockers and doornails. The inner door (the interior room door) can be made into wooden double-leaf doors, dual-fan grille door and single-leaf lattice doors with exquisite carvings.

The courtyard door, as the face of the entire building, fully manifests the class of buildings and the power and position of the master. The forceful heavy solid style and the awe-inspiring sense are both important. In the process of door decoration, the owner reposes the good wishes of the family in this square land. The paintings on the door and the stone lions in front of the door have become an important place for the sustenance of good wishes. All these are made of wood carving or color painting whose themes are full of variety from people, animals, and plants to the vessels and all good things that can be seen in everyday life. These themes are also given other different meanings. In addition, door components are both with aesthetic form and practical function, such as the door auxiliary for suppressing evil spirits, the knocker for absorbing auspice, door pin for sustaining the family line, the lintel for peace and the doornail for maintaining a thriving family. They are ideological symbol of Naxi people, bearing their spirit.

Doors' decoration is paid more attention because of its location. Naxi houses' doors are usually grille door or lattice doors with both blocking and transmittance function. The lattice door is made of wood underneath and lattice shape upward combining the function of the door and window. Grille door is installed between two pillars, setting four, six or more fan door according to the column distance. The doors are always double in number to ensure that the two are able to open in the center at the same time. The door of this structure is more flexible in use and its manufacturing structure is also unified. Although the grid heart decoration has to meet the requirements of translucent function, grid stripes can be the combination of a variety of ever-changing geometric patterns embedded in small piece of wood carvings, such as pomegranates, lotus, peach, bats, birds and other animals. Despite the small size, such symbolic carvings are highly skilled and full of visual aesthetics and cultural connotations. Because the apron below Grille doors is not the visual center, the decoration is simply carved in bas-relief pattern or geometric pattern border. The annular plate in the middle of the segregation fan is people's sight with bright light. Since it is a piece of wood, it can be carved arbitrarily and becomes the focus of the sliding door decoration. In some of the more luxurious residential buildings, the annular board is carved by figures and the scene composition with plots. Every fan window takes its own look and is rarely identical completely. 
When People look at the segregation fan window, they are like watching a group of comic strips with lots of fun. If two vertical sides of the segregation fan window have the annular board, the layout of the decoration is relatively simple due to their location of being far away from people's sight. Most of such kind of fans will only be decorated with one simple pattern rather than using the episode of woodcarving and a few of them will adopt the same content.

Inadequacies of traditional door decoration materials .Naxi traditional door decoration made of natural wood. As an organic material, wood has fresh texture, soft feel and comfortable feeling, offering senses of warmness and geniality. It is also quite good for one's physical and mental health. It merges with the life of the Naxi people with its amazing practical function and Naxi people's exquisite carving skills. However, wood also has many weaknesses. For example, forest resources are limited. The growth cycle of trees is long. Timber is flammable, easily deformed with water. The paint fades after sun exposure and it cannot be recycled. These "defects" cause more and more Naxi people trying to explore the use of new decorative materials.

\section{The appropriate use of new materials in Naxi residential door trims' decoration}

The Open and inclusive characteristics of Naxi people determine their taste in the pursuit of beauty for inclusiveness and culture tolerance. In their views, nothing can limit and define beauty. All that can give people comfortable and enjoyable feelings are beautiful things, regardless of where it comes from or what kind of background it is. Naxi people absorb things that are beautiful, good and useful into their culture, which enriches their own culture and also develops it [2]. With the progress of society, the home decoration industry develops rapidly. New decorative materials appear one after another. Influenced by Bai, Han and other ethnic groups, today's Naxi people apply materials such as iron, aluminum alloy in the door trims decoration, which not only to make up for the inadequacies of the natural wood, but also highlights the Naxi inclusive and eclectic characteristics.

The Forefathers said, "Learning from each other is like grinding stone and polishing jade”. On the basis of maintaining the original style of the building, to explore the usage of iron, aluminum alloy and the new generation of wood substitute materials, mining gives full play to the the advantages of the material itself and maintains the original architectural form and style, which achieves unity.

The appropriate use of iron, aluminum alloy and the new generation of wood substitute materials. In today's Naxi villages, the iron doors has begun to replace the wooden doors in the decoration of the outside door (the courtyard door) in residential courtyards. Iron doors still meet the requirements of Naxi traditional spiritual function with doornails, door knockers, door auxiliary and door painting. This would explain that the function of doors and their spiritual significance has not changed. The subtle change is its material from traditional wood to iron. Compared to natural wood, Iron is more cost-effective, secure, stable, and persistent in use. The iron door is painted with different colors according to the taste and interest of the master, adding vivid loveliness to the slightly dull wood construction.

The aluminum alloy doors and windows which are popular in Han people's architectural decoration begin to emerge in the inner door (the interior room door)'s decoration. However, the use of aluminum alloy is not common, accounting for only a small proportion of the doors and windows. The decorative segregation fan windows retains, offering exquisite carvings the stage to show out. Aluminum alloy is mainly used in the door of Naxi style building inn for visitors to live, which maintains Naxi dwellings' original style and strengthens barrier function of the door to meet people's needs.

Walking in the Naxi settlements - the ancient city of Lijiang, you will see that the doors of street shops become newer and newer. These new grille door which is yellower and newer, though maintains the original double-leaf and the carved window lattice, the style, doesn't have the primitive and traditional flavor. Naxi people are kind and smart. Instead of extorting precious wood from the forest, they learn advanced skills and actively use the new generation of wood substitute materials. For instance, they make wood-plastic composite material by mixing wood scraps, 
sawdust, wood flour, recycled plastic and other elements together. This material is a part of alternative wood materials which protects the forest and resources. It also solves pollution problem due to the fact that the waste plastics can not be recycled, fully utilizing waste resources. The most important thing is that the wood-plastic composite material is similar to natural wood, so decorative wood-plastic composite material can almost achieve logs' artistic effect [3]. Another example is the modified wood materials in modern processing technology, such as compressed wood, curved wood, stained wood, preservative wood, flame retardant wood etc, and artificial wooden materials, such as plywood, fiberboard, planing skateboard, wooden artificial imitation wood, bark artificial materials, wood molded products, wood inorganic glue wood-based panels and so on. Naxi people have created the new grille doors and windows to meet the beauty standard of timber, function and technology by combining these new technologies with their own architectural characteristics.

Decorative themes evolve with new materials. The application of Iron, aluminum, and the new generation of wood substitute materials has changed Naxi door trims' decoration. For instance, because of the characteristics of the material itself, the iron doors and aluminum windows and doors can not be directly decorated on. If a building has adopted a simple style of iron and aluminum alloy, using the original complicated decorative techniques appears to be too burdensome. Due to this reason, Naxi people have simplified the decorative themes. For example, in the process of wood carving, they make the plant into imagery by removing part of the foliage and reducing the number of petals to truncate plants into their general shapes. This handling of the architectural maintains a more unified style between materials and the decoration.

The new type of grille door combines with the new generation of wood substitute materials with modern techniques. Since new materials are easy to compress and easy to bend, the new type of grille door is easier to shape with stronger three-dimensional visual effect and richer themes than the traditional grille doors. More vivid flowers animals, birds and insects can be carved on it. Compared with the traditional paint, the new wood-gloss varnish which enhances the smoothness of wood surface is superior in terms of stability, persistence, environmental protection or the aesthetic value.

\section{Conclusions}

Under the exchange and integration of the multi-ethnic and multi-form culture conflict, Naxi door trims' decorative art with a strong ethnic feature and regional character is undergoing a revolution. In this process, the unique Naxi culture cultivation and aesthetic taste and style and their open, inclusive, eclectic characteristics and bold spirit of innovation since ancient times have played an important role. They have applied the latest wave of skills and materials appropriately to the original architectural door trim decoration creating harmonious collision between antiquity and modernity in today's Naxi tribes. Historic, hardworking and intelligent Naxi people are bound to follow the trend to compose the most beautiful notes for the Harmonious sound spectrum in their door trim decoration culture.

\section{References}

[1] Lin Shasha, Liu Su. On the architectural form of Naxi residence in the ancient city of Lijiang [J]. The sixteenth residential Conference Proceedings (the first volumn) .2008:162.

[2] Hu Qian. Analysis of decorative arts of the doors and windows of the Lijiang Naxi traditional houses [D], Master’s degree, Kunming University of Science and Technology, 2010.

[3] Qiaoling Gui, Feng Su, Ruibo Hu, Xiaoyan Liu.Innovative Use of Wood Materials in Modern Home Design [J]. Applied Mechanics and Materials, 2012, Vols.204-208 :4156-4160.

[4] Wang Yuexin. Research of Chinese traditional door trim decoration art [D], Master's degree, Northeast Normal University, 2007.

[5] Wu Hao, Yu Wenbo, Designs and materials - On Wood [J]. New Decoration and New Materials.2004,2 (4) :41-43

[6] Ruibo Hu, Jingyuan Li, Liyan Chen, Renping Xu, Kunqian Wang, Xingran Mao. Application 
Study of Conceptual Design in the Product Design[J]. Applied Mechanics and Materials, 2012, Vols. 121-126: 730-734. (EI: 20114714533309)

[7] Ruibo Hu, Renping Xu, Kunqian Wang, Jingyuan Li. The Research of Virtual Tactile Design Application in Dongba Sculpture[J]. Advanced Materials Research, 2011, Vols. 228-229: 185-190. (EI: 20112113994664)

[8] Ruibo Hu, Renping Xu, Kunqian Wang, Xingran Mao. The Research of Developing and Constructing Tourist Attractions in Dong Jiahe[J]. Advanced Materials Research, 2011, Vols. 250-253: 3884-3888. (EI: 20112314040542) 